\title{
Effects of Antenatal Magnesium Exposure on Intestinal Blood Flow and Outcome in Preterm Neonates
}

\author{
Tugba Gursoy, MD ${ }^{1}$ Ebru Yalin Imamoglu, MD ${ }^{2}$ Fahri Ovali, MD² Guner Karatekin, MD² \\ ${ }^{1}$ Neonatal Intensive Care Unit, Department of Pediatrics, Koc \\ University School of Medicine, Istanbul, Turkey \\ 2 Neonatal Intensive Care Unit, Zeynep Kamil Maternity and Children's \\ Training and Research Hospital, Istanbul, Turkey \\ Address for correspondence Tugba Gursoy, MD, Department of \\ Pediatrics, Koc University School of Medicine, Rumeli Feneri Yolu, \\ Sarıyer, Istanbul, 34450, Turkey (e-mail: tgursoy@ku.edu.tr).
}

Am J Perinatol 2015;32:1064-1069.

\author{
Abstract \\ Keywords \\ - blood flow \\ - doppler ultrasound \\ - magnesium \\ - superior mesenteric \\ artery \\ - preterm infant
}

Objective This study aims to investigate the effects of antenatal magnesium sulfate on intestinal blood flow in preterm neonates.

Study Design In this prospective case-match study, 25 preterm neonates exposed to magnesium sulfate antenatally were included (study group). Overall, 25 gestational age-matched neonates who had no exposure to magnesium constituted the control group. Serial daily Doppler flow measurements of superior mesenteric artery (SMA) were performed. The time to reach full feeds, first meconium passage were assessed. Presence of feeding intolerance or necrotizing enterocolitis was recorded.

Results Blood flow velocities of SMA were not different between the groups during the first five postnatal days. However, SMA blood flow showed an increasing trend in the control group unlike the study group (control group, $p<0.001$; study group, $p=0.29$ ). There was no significant difference between the two groups regarding the time to reach full feeds or first meconium passage and presence of feeding intolerance. No case of necrotizing enterocolitis was seen.

Conclusion Antenatal magnesium does not significantly affect intestinal blood flow, but it seems to attenuate the increasing trend of the intestinal blood flow in the early postnatal days. However, this study failed to show any impact of this finding on clinical outcomes.
Antenatal magnesium sulfate $\left(\mathrm{MgSO}_{4}\right)$ is used widely as a tocolytic agent in preterm labor and as an antihypertensive agent in preeclampsia. Although used widely, its influence on the neonatal circulatory system is unclear and may be associated with adverse neonatal outcomes. ${ }^{1}$ There are controversial reports about its effect on the incidence of patent ductus arteriosus (PDA) ${ }^{1-5}$ and hypotension. ${ }^{1,6,7}$

Less is known about the effect of antenatally administered $\mathrm{MgSO}_{4}$ on the gastrointestinal system. Adequate perfusion of intestines is essential for the normal development of the intestinal mucosa. ${ }^{8}$ Blood flow (BF) disturbances are part of the etiology of neonatal abdominal disorders. ${ }^{9}$ Pathological

received

November 2, 2014

accepted after revision

February 3, 2015

published online

March 31, 2015

BF parameters in the SMA were reported to predict problems of intestinal motility and tolerance of enteral feeding. ${ }^{8}$

Most of the effects of magnesium are because of its role in the regulation of the vascular tone. ${ }^{10}$ Therefore, in this study we aimed to evaluate the effect of antenatal magnesium exposure on the intestinal BF and clinical signs of gastrointestinal problems in the early postnatal days in preterm neonates.

\section{Patients and Methods}

This prospective case-match study was performed at Zeynep Kamil Maternity and Children's Training and Research

Copyright $\odot 2015$ by Thieme Medical Publishers, Inc., 333 Seventh Avenue, New York, NY 10001, USA. Tel: +1(212) 584-4662.
DOI http://dx.doi.org/ 10.1055/s-0035-1548541. ISSN 0735-1631. 
Hospital between December 2011 and April 2013. A total of 25 appropriate for gestational age infants who were born between 26 and 34 gestational weeks and whose mothers were exposed to antenatal $\mathrm{MgSO}_{4}$ therapy were included in the study group. Successive 25 birth weight and gestational age-matched neonates whose mothers did not receive any $\mathrm{MgSO}_{4}$ therapy constituted the control group. Infants with absence of antenatal Doppler examination or presence of absent/reversed end diastolic velocity in umbilical artery, congenital malformation, perinatal asphyxia, and chorioamnionitis were not included in this study.

A loading dose of $6 \mathrm{~g}$ of $\mathrm{MgSO}_{4}$ was infused over 30 minutes and was followed by a maintenance infusion of $0.8 \mathrm{~g} / \mathrm{h}$ until the time of delivery. Maternal serum magnesium concentration just before labor was retrieved from the maternal records. Maternal cumulative $\mathrm{MgSO}_{4}$ dose and total infusion time were calculated. Cord blood magnesium levels were obtained. Atomic absorption spectrophotometer (Cobas Integra 800, Roche, Switzerland) was used to determine serum magnesium levels.

Informed consent was obtained from the parents and study protocol was approved by local ethics committee.

\section{Doppler Ultrasonography Measurements}

Flow imaging and BF velocity were obtained with an echocardiography machine (Philips En Visor C, Philips, Amsterdam, the Netherlands) and a multifrequency of 5 to $12 \mathrm{MHz}$ sector probe was used.

Superior mesenteric artery (SMA) was used to assess intestinal BF. Daily serial Doppler assessment of SMA included peak systolic velocity (PSV), end diastolic velocity (EDV), mean velocity (MV), and resistance index (RI $=$ PSV - EDV/ PSV) and were done between the first and the fifth postnatal days, the first assessment done in the first 18 to 24 hours of life to diminish flow metric modifications that can be influenced by postnatal adaptation seen in the first hours of life. ${ }^{11}$ As elevated levels of MgSO4 may persist for up to 7 days, with an elimination half-life of 43.2 hours, ${ }^{12}$ we performed SMA Doppler measurements for 5 consecutive days.

The SMA was identified at its emergence from the abdominal aorta, localized by real-time imaging on a horizontal abdominal section and Doppler signals were sampled a few millimeters from its origin using a gate size of $0.6 \mathrm{~mm}$. The angle between the ultrasound beam and $\mathrm{BF}$ in the vessel was close to 0 degrees (range, $0-20$ degrees). Five consecutive and homogeneous cardiac cycles were measured and their mean was calculated for analysis. Immediately after flow velocity measurements were taken, the internal diameter of the SMA was assessed with two-dimensional imaging. The average of three measurements was taken for the calculation of $\mathrm{BF}$ :

$\mathrm{SMABF}=\mathrm{SMAMV} \times\left(\pi D^{2} / 4\right) \times 60$, where $D$ stands for the vessel diameter.

All measurements were done preprandially to eliminate the effect of feeding on the SMA BF. ${ }^{9}$

The practice of initiation of feedings was the same for both the groups. Depending on the birth weight and gestational age,
10 to $20 \mathrm{~mL} / \mathrm{kg}$ of breast milk or formula was initiated on the first postnatal day if the infant tolerated the feeding. The amount of feeding was increased based on birth weight $(10-15 \mathrm{~mL} / \mathrm{kg} / \mathrm{d}$ for 750-1000 g; $20 \mathrm{~mL} / \mathrm{kg} / \mathrm{d}$ for 1,000-1,500 g birth weight and $30 \mathrm{~mL} / \mathrm{kg} / \mathrm{d}$ for $>1,500 \mathrm{~g}$ birth weight).

The time to reach full feeds, first meconium passage were assessed. The type of feeds and presence of feeding intolerance or necrotizing enterocolitis (NEC) were recorded.

Feeding intolerance was defined by the presence of gastric residuals (more than 50\% of feed on consecutive feedings), abdominal distension, vomiting that resulted in failure to make the daily increments in feeding.

The grade of intraventricular hemorrhage (IVH) was reported according to the criteria of Papile et al. ${ }^{13}$ Hemodynamically significant PDA was defined when the ductal diameter was measured more than $1.6 \mathrm{~mm}$ and the PDA flow was growing or pulsatile with left-to-right shunt. ${ }^{14}$

\section{Statistical Analysis}

Statistical analysis was performed by using statistical package for the social sciences (SPSS, Chicago, IL). The variables were investigated using visual histograms, probability plots, and Shapiro-Wilk test to determine whether or not they are normally distributed. Descriptive analyses were presented using means \pm SD for normally distributed variables, as medians (range, 25-75\%) for the nonnormally distributed variables and as percentages for categorical variables. Normally distributed variables were compared by Student $t$-test, nonparametric variables by Mann-Whitney $U$ test, and categorical variables by chi-square test. Friedman tests were conducted to test whether there is a significant change in parameters in the consecutive days. Correlations were evaluated by using the Spearman correlation coefficient.

Intraobserver variability was assessed in an arbitrary sample of 20 neonates. The measurements were repeated by the same investigator who was blinded to the previous results. The coefficient of variation was calculated and intraobserver error was minimal (2\%).

\section{Results}

Demographic and clinical data of the groups are given in - Table 1. The indications for the use of MgSO4 was preeclampsia in 16 (64\%) of the cases and tocolysis in 9 (34\%) cases. Median total dose of $\mathrm{MgSO}_{4}$ given to the mother before labor was 34.2 (range, 13.3-54.4) g. Median infusion time was 15 (range, 4.3-26) hours. Mean serum magnesium levels in maternal and cord blood were $5.4 \pm 1.1$ and $3.5 \pm 0.7 \mathrm{mmol} / \mathrm{L}$, respectively, and the $\mathrm{Mg}$ levels of the neonates exposed to $\mathrm{MgSO}_{4}$ antenatally decreased to $2.7 \pm 0.4 \mathrm{mmol} / \mathrm{L}$ on the fifth postnatal day. Cord blood magnesium levels of the neonates correlated with maternal serum magnesium levels $(r=0.89, p<0.001)$.

BF velocities, RI, and BF of SMA did not differ between the groups (-Table 2). However, SMA diameter was higher in the study group. No case of hypotension or hypertension was observed in both the groups and mean blood pressure did not correlate with BF or velocities measured in any study day in 
Table 1 Demographic and clinical data of the groups

\begin{tabular}{|l|l|l|l|}
\hline & Control group, $\boldsymbol{n}=\mathbf{2 5}$ & Study group, $\boldsymbol{n}=\mathbf{2 5}$ & $\boldsymbol{p}$ Value \\
\hline Birth weight (g) & $1,545 \pm 304$ & $1,524 \pm 300$ & 0.71 \\
\hline Gestational age (wk) & $30.9 \pm 1.9$ & $31.2 \pm 1.8$ & 0.14 \\
\hline Female, $n$ (\%) & $16(64)$ & $14(56)$ & 0.56 \\
\hline 5 minute Apgar score & $7(4-8)$ & $7(6-8)$ & 0.5 \\
\hline C/S, $n$ (\%) & $21(84)$ & $22(88)$ & 0.68 \\
\hline Antenatal steroid exposure, $n$ (\%) & $19(76)$ & $23(92)$ & 0.034 \\
\hline Respiratory distress syndrome, $n$ (\%) & $8(32)$ & $8(32)$ & 1 \\
\hline Patent ductus arteriosus, $n$ (\%) & $7(28)$ & $4(16)$ & 0.3 \\
\hline Intracranial hemorrhage (stage 1-2), $n$ (\%) & $2(8)$ & $3(12)$ & 0.83 \\
\hline Cord blood Mg (mmol/L) & $1.9 \pm 0.3$ & $3.5 \pm 0.7$ & $<0.001$ \\
\hline Postnatal 5th day serum Mg (mmol/L) & - & $2.7 \pm 0.4$ & \\
\hline The time of first stool passage (d) & $1(1-2)$ & $1(1-1)$ & 0.18 \\
\hline Time to achieve full enteral feed (d) & $6(5-8.5)$ & $6(5-10)$ & 0.84 \\
\hline Feeding intolerance, $n$ (\%) & $2(8)$ & $6(24)$ & 0.12 \\
\hline
\end{tabular}

both groups ( $r<0.25$ and $p>0.2$ for all correlations). BF correlated with birth weight and gestational age of the infants in both the groups ( $r>0.45$ and $p<0.01$ for all correlations). Therefore, BF per $\mathrm{kg}$ was calculated and it was not different between the groups also (-Table 2 ).

Peak systolic, end diastolic, mean velocity, BF, and BF per $\mathrm{kg}$ together with SMA diameter and mean BP showed statistically significant increasing trend toward the fifth postnatal day in the control group (-Table 2). However, this was not observed in the study group.

There was no significant difference between the two groups regarding the time to reach full feeds or first meconium passage, type of feeds (six neonates in the control, three neonates in the study group received only formula, and the others received breast milk mostly), and presence of feeding intolerance (-Table 1). No case of NEC was seen.

\section{Discussion}

In this study, SMA BF velocities and flows were not different between the neonates who were exposed to antenatal $\mathrm{MgSO}_{4}$ or not. However, as might be expected, because of the vasodilator effects of $\mathrm{Mg}$, SMA diameter was higher in the neonates exposed to $\mathrm{MgSO}_{4}$. There was a statistically significant increasing trend in BF velocities, BF and SMA diameter in the control group from the first to the fifth postnatal day which was not seen in the neonates exposed to $\mathrm{MgSO}_{4}$. Nevertheless, we failed to show any significant clinical adverse effect that can be attributed to these changes in the hemodynamics of SMA BF.

Magnesium was shown to induce vasodilation and increased BF velocity in the cerebral vessels of preeclamptic women. ${ }^{15}$ Increased magnesium levels were found to decrease the vascular tonus of the arteries in dogs. ${ }^{16}$ It has a concentration-dependent vasodilatory effect on cerebral and mesenteric vascular beds and the response differs in each vascular bed. ${ }^{17}$ This might explain the lack of magnesium effect on the SMA flow observed in this study. On the contrary, higher magnesium levels observed in the study group on the first postnatal day decreased gradually on the following days. This might be the reason why we did not observe the increasing trend of the intestinal $\mathrm{BF}$ on the following days in the group exposed to $\mathrm{MgSO}_{4}$.

Measurement of the vessel diameter is very critical in the calculation of BF as both the diameter of the vessel is very small and square of this measurement is taken for the calculation so errors up to $30 \%$ can occur in flow calculations. ${ }^{18}$ The SMA BFs per kg in this study are lower than those in the study of Van Bel et al $(43 \mathrm{~mL} / \mathrm{min} / \mathrm{kg})$, though the velocities are similar. ${ }^{18}$ As expected, this difference comes from the measurement of vessel diameter. In this study, diameter of SMA is between 1.6 and $1.8 \mathrm{~mm}$, whereas it was between 2.2 and $2.7 \mathrm{~mm}$ in their study. This difference might be because of the different methods used for the measurement of the diameter. In their study, M-mod was used to measure the diameter instead of two-dimensional imaging which was used in our study. In M-mod method, the cursor should be perpendicular to the vessel wall; small deviations from that angle will result in erroneously higher vessel diameter measurement. However, as all the measurements are done by the same observer and intraobserver error is acceptable (2\%), we think that this did not compromise our results. Besides, SMA BFs in our study correlated significantly with both birth weight and gestational age of the infants such as the study of Van Bel et al. ${ }^{18}$

NEC is a multifactorial disease and one of the factors involved in its pathogenesis is the disturbance of intestinal $\mathrm{BF} . \mathrm{MgSO}_{4}$ attenuates peroxide-induced vasoconstriction by inhibiting thromboxane synthesis which is implicated in the pathogenesis of NEC. ${ }^{19}$ It also inhibits platelet activation 
Table 2 Blood flow velocities, RI, diameter, and blood flow of SMA together with mean blood pressure in the control and the study group in the first 5 postnatal days

\begin{tabular}{|c|c|c|c|c|c|c|}
\hline & Day 1 & Day 2 & Day 3 & Day 4 & Day 5 & $p^{\mathrm{a}}$ \\
\hline \multicolumn{7}{|l|}{ SMA MV (cm/sec) } \\
\hline Control group & $27.8(23.1-29)$ & $26.4(23.1-31.9)$ & $30.2(24.6-36.4)$ & $31.4(25.2-37.3)$ & $\begin{array}{l}32.2 \\
(29.2-38.3)\end{array}$ & $<0.001$ \\
\hline Study group & $26.5(18.7-34)$ & $28.8(24.6-32.4)$ & $28.9(21.3-38.1)$ & $27.8(21.6-36.3)$ & $\begin{array}{l}25.7 \\
(21.7-38.9)\end{array}$ & 0.22 \\
\hline$p$ & 0.92 & 0.44 & 0.6 & 0.15 & 0.13 & \\
\hline \multicolumn{7}{|c|}{ SMA PSV (cm/sec) } \\
\hline Control group & $62.1(50.3-73.6)$ & $63.3(52.3-82.1)$ & $72.1(58.4-87.3)$ & $80.4(69.4-96.03)$ & $\begin{array}{l}80.5 \\
(71.1-95.8)\end{array}$ & $<0.001$ \\
\hline Study group & $57.8(48.5-73.1)$ & $64.6(55.6-94.4)$ & $80(50.2-87.4)$ & 74.8 (53.2-89.1) & $\begin{array}{l}78.1 \\
(53.3-109.5)\end{array}$ & 0.2 \\
\hline$p$ & 0.95 & 0.79 & 0.95 & 0.17 & 0.31 & \\
\hline \multicolumn{7}{|c|}{ SMA EDV $(\mathrm{cm} / \mathrm{sec})$} \\
\hline Control group & $11.7(6.7-16.1)$ & $12.1(9.2-16.7)$ & $12.7(10.6-16.2)$ & $13.6(10.1-19.2)$ & $\begin{array}{l}15.9 \\
(12.4-20.1)\end{array}$ & 0.002 \\
\hline Study group & $14.5(8.7-17.8)$ & $13.3(11.1-19.2)$ & $13.3(9-18.1)$ & $13.4(8.8-15.6)$ & $\begin{array}{l}14.3 \\
(11.1-17.5)\end{array}$ & 0.91 \\
\hline$p$ & 0.39 & 0.33 & 0.92 & 0.37 & 0.15 & \\
\hline \multicolumn{7}{|l|}{ SMA RI } \\
\hline Control group & $0.79(0.71-0.91)$ & $0.79(0.74-0.85)$ & $0.79(0.75-0.85)$ & $0.81(0.77-0.87)$ & $\begin{array}{l}0.79 \\
(0.76-0.82)\end{array}$ & 0.68 \\
\hline Study group & $0.77(0.72-0.83)$ & $0.8(0.68-0.86)$ & $0.79(0.77-0.84)$ & $0.81(0.78-0.83)$ & $\begin{array}{l}0.83 \\
(0.73-0.84)\end{array}$ & 0.49 \\
\hline$p$ & 0.93 & 0.84 & 0.88 & 0.87 & 0.62 & \\
\hline \multicolumn{7}{|l|}{ SMA BF (mL/min) } \\
\hline Control group & $33.5(27.9-42.8)$ & $35.3(29.8-49.2)$ & $31(40.8-55.4)$ & $43.4(36.8-55.2)$ & $\begin{array}{l}49.8 \\
(37.1-56.7)\end{array}$ & $<0.001$ \\
\hline Study group & $37.8(25.9-55.8)$ & $44.3(36.3-54)$ & $48.9(29.4-62.6)$ & $45.6(27.1-55.5)$ & $49(31.4-72.6)$ & 0.29 \\
\hline$p$ & 0.35 & 0.13 & 0.64 & 0.95 & 0.92 & \\
\hline \multicolumn{7}{|c|}{ BF per $\mathrm{kg}(\mathrm{mL} / \mathrm{min} / \mathrm{kg})$} \\
\hline Control group & $22(18.7-26.6)$ & $23.9(19.4-30.5)$ & $25.9(20.6-36.2)$ & $29(22.2-36.2)$ & $\begin{array}{l}30.8 \\
(24.4-34.6)\end{array}$ & $<0.001$ \\
\hline Study group & $27.2(18.7-32.9)$ & $29.4(27.9-33.4)$ & $29.9(22.8-38.4)$ & $31.5(20.4-34.8)$ & $\begin{array}{l}31.9 \\
(22.2-46.6)\end{array}$ & 0.29 \\
\hline$p$ & 0.16 & 0.028 & 0.29 & 0.87 & 0.62 & \\
\hline \multicolumn{7}{|c|}{ SMA diameter (mm) } \\
\hline Control group & $1.6(1.51-1.8)$ & $1.63(1.51-1.9)$ & $1.64(1.51-1.9)$ & $1.7(1.5-1.9)$ & $\begin{array}{l}1.72 \\
(1.5-1.9)\end{array}$ & 0.012 \\
\hline Study group & $1.79(1.6-1.9)$ & $1.8(1.67-1.9)$ & $1.8(1.7-1.97)$ & $1.76(1.7-1.9)$ & $\begin{array}{l}1.79 \\
(1.7-1.97) \\
\end{array}$ & 0.11 \\
\hline$p$ & 0.057 & 0.052 & 0.026 & 0.16 & 0.09 & \\
\hline \multicolumn{7}{|c|}{ Mean BP $(\mathrm{mm} \mathrm{Hg})$} \\
\hline Control group & $44(41-50)$ & $45(43-51)$ & $48(44-51)$ & $48(46-54)$ & $50(48-56)$ & $<0.001$ \\
\hline Study group & $49(43-58)$ & $50(44-57)$ & $54(45-59)$ & $53(46-57)$ & $52(45-58)$ & 0.62 \\
\hline$p$ & 0.09 & 0.033 & 0.043 & 0.1 & 0.97 & \\
\hline
\end{tabular}

Abbreviations: BF per kg, blood flow per kg body weight; BP, blood pressure; SMA BF, superior mesenteric artery blood flow, SMA EDV, superior mesenteric artery end diastolic velocity; SMA MV, superior mesenteric artery mean velocity; SMA PSV, superior mesenteric artery peak systolic velocity; SMA RI, superior mesenteric artery resistive index. ${ }^{a} p$ Values (Friedman test) stand for the significance of change in the mentioned parameters from day 1 to day 5. 
induced by adenosine diphosphate which results in release of vasoactive substances. ${ }^{19}$ Therefore, magnesium was thought to be a hope for the prevention of NEC, however, studies failed to show any relation between them. ${ }^{5,19}$ Although the diameter of SMA was significantly higher in $\mathrm{MgSO}_{4}$ exposed group in this study, this did not result in increased mesenteric BF. As there was no case of NEC in this study, we could not make any conclusion on this issue.

Antenatal $\mathrm{MgSO}_{4}$ administration to the mother was accepted as a risk factor for a meconium ileus especially in lowbirth-weight infants. ${ }^{20}$ The effect of $\mathrm{MgSO}_{4}$ on the timing of first stool is controversial. While Brazy et $\mathrm{al}^{21}$ reported that $\mathrm{MgSO}_{4}$ delayed the passage of first stool; others failed to show such an effect like our study. ${ }^{22,23}$ In a previous study, it was shown that infants whose SMA flows did not increase after feeding reached full enteral feeding later than the infants whose SMA flows increased postprandially. ${ }^{24}$ Also, these infants showed signs of feeding intolerance more often. ${ }^{24}$ In this study, we did not make any postprandial measurements but the increase observed in SMA BFs and diameter on the consecutive days in the control group was not observed in the $\mathrm{MgSO}_{4}$ exposed infants. However, the higher incidence of feeding intolerance observed in the $\mathrm{MgSO}_{4}$ exposed infants (24 vs. 8\%) did not reach to statistical significance which might be because of the limited sample size. A large study might have yielded significance.

Magnesium also has effects on neuromuscular junction where muscle contraction is regulated by calcium flux. ${ }^{25}$ In turn, magnesium controls the calcium flux and parenterally administered $\mathrm{MgSO}_{4}$ relaxes both smooth and striated muscle by antagonizing these calcium fluxes. ${ }^{25}$ Orally administered magnesium can cause diarrhea. ${ }^{26} \mathrm{MgSO}_{4}$ is used as a laxative and this effect is based on acceleration of the small intestine transit time. ${ }^{26}$ On the contrary, it is also reported to slow gastric emptying. ${ }^{27}$ However, it is difficult to draw a conclusion on these subjects as we did not evaluate gastric or intestinal transit time. The only parameter we examined was the time of first stool passage which did not differ between the groups.

There are some limitations of this study. First of all, the infants included in this study were relatively mature (31 weeks), therefore not really in the gestational age range of infants who have significant problems with feeding and NEC. Second, the study has not enough power to demonstrate clinical outcomes.

To our knowledge, this study is the second study evaluating the effect of $\mathrm{MgSO}_{4}$ on the intestinal $\mathrm{BF}$. In the previous study, they also measured SMA BF velocity and concluded that antenatal exposure to $\mathrm{MgSO}_{4}$ did not affect intestinal BF in the first 24 hours of life. ${ }^{10}$ Their measurements of blood velocities were also similar to the results of our study. However, they found a significant negative relation between the mean blood velocity and the time from birth to the time when BF measurement was done which was in conflict with the findings of our study. The previous study was retrospective and they did one measurement per neonate at a varying time from birth.

This is the first prospective study with relatively few confounding factors reporting serial intestinal BF that shows change over time. Antenatal magnesium does not significantly affect intestinal $\mathrm{BF}$, but it seems to attenuate the increasing trend of the intestinal BF in the early postnatal days. However, this has no effect on the gastrointestinal symptoms. Randomized controlled studies with a larger sample size with smaller gestational age infants should be performed to make a more precise conclusion.

\section{Conflict of Interest \\ None.}

\section{References}

1 Paradisis M, Osborn DA, Evans N, Kluckow M. Randomized controlled trial of magnesium sulfate in women at risk of preterm delivery-neonatal cardiovascular effects. J Perinatol 2012;32(9): 665-670

2 Shokry M, Elsedfy GO, Bassiouny MM, Anmin M, Abozid H. Effects of antenatal magnesium sulfate therapy on cerebral and systemic hemodynamics in preterm newborns. Acta Obstet Gynecol Scand 2010;89(6):801-806

3 del moral T, Gonzalez-Quintero VH, Claure N, Vanbuskirk S, Bancalari E. Antenatal exposure to magnesium sulfate and the incidence of patent ductus arteriosus in extremely low birth weight infants. J Perinatol 2007;27(3):154-157

4 Katayama Y, Minami H, Enomoto M, Takano T, Hayashi S, Lee YK. Antenatal magnesium sulfate and the postnatal response of the ductus arteriosus to indomethacin in extremely preterm neonates. J Perinatol 2011;31(1):21-24

5 Elimian A, Verma R, Ogburn P, Wiencek V, Spitzer A, Quirk JG. Magnesium sulfate and neonatal outcomes of preterm neonates. J Matern Fetal Neonatal Med 2002;12(2):118-122

6 Rouse DJ, Hirtz DG, Thom E, et al; Eunice Kennedy Shriver NICHD Maternal-Fetal Medicine Units Network. A randomized, controlled trial of magnesium sulfate for the prevention of cerebral palsy. N Engl J Med 2008;359(9):895-905

7 Rantonen T, Kääpä P, Grönlund J, et al. Maternal magnesium sulfate treatment is associated with reduced brain-blood flow perfusion in preterm infants. Crit Care Med 2001;29(7):1460-1465

8 Robel-Tillig E, Knüpfer M, Pulzer F, Vogtmann C. Blood flow parameters of the superior mesenteric artery as an early predictor of intestinal dysmotility in preterm infants. Pediatr Radiol 2004; 34(12):958-962

9 Leidig E. Doppler analysis of superior mesenteric artery blood flow in preterm infants. Arch Dis Child 1989;64(4 Spec No): 476-480

10 Havranek T, Ashmeade TL, Afanador M, Carver JD. Effects of maternal magnesium sulfate administration on intestinal blood flow velocity in preterm neonates. Neonatology 2011;100(1):44-49

11 Pezzati M, Dani C, Biadaioli R, et al. Early postnatal doppler assessment of cerebral blood flow velocity in healthy preterm and term infants. Dev Med Child Neurol 2002;44(11):745-752

12 Dangman BC, Rosen TS. Magnesium levels in infants of mothers treated with MgSO4. Pediatr Res 1977;11:415 (abstract 262)

13 Papile LA, Burstein J, Burstein R, Koffler H. Incidence and evolution of subependymal and intraventricular hemorrhage: a study of infants with birth weights less than 1,500 gm. J Pediatr 1978; 92(4):529-534

14 Su BH, Watanabe T, Shimizu M, Yanagisawa M. Echocardiographic assessment of patent ductus arteriosus shunt flow pattern in premature infants. Arch Dis Child Fetal Neonatal Ed 1997;77(1): F36-F40

15 Belfort MA, Saade GR, Moise KJ Jr. The effect of magnesium sulfate on maternal and fetal blood flow in pregnancy-induced hypertension. Acta Obstet Gynecol Scand 1993;72(7):526-530 
16 Altura BT, Altura BM. Withdrawal of magnesium causes vasospasm while elevated magnesium produces relaxation of tone in cerebral arteries. Neurosci Lett 1980;20(3):323-327

17 Euser AG, Cipolla MJ. Resistance artery vasodilation to magnesium sulfate during pregnancy and the postpartum state. Am J Physiol Heart Circ Physiol 2005;288(4):H1521-H1525

18 Van Bel F, Van Zwieten PH, Guit GL, Schipper J. Superior mesenteric artery blood flow velocity and estimated volume flow: duplex Doppler US study of preterm and term neonates. Radiology 1990; 174(1):165-169

19 Ghidini A, Espada RA, Spong CY. Does exposure to magnesium sulfate in utero decrease the risk of necrotizing enterocolitis in premature infants? Acta Obstet Gynecol Scand 2001;80(2):126-129

20 Emil S, Nguyen T, Sills J, Padilla G. Meconium obstruction in extremely low-birth-weight neonates: guidelines for diagnosis and management. J Pediatr Surg 2004;39(5):731-737

21 Brazy JE, Grimm JK, Little VA. Neonatal manifestations of severe maternal hypertension occurring before the thirty-sixth week of pregnancy. J Pediatr 1982;100(2):265-271
22 Kumar SL, Dhanireddy R. Time of first stool in premature infants: effect of gestational age and illness severity. J Pediatr 1995;127(6): 971-974

23 Verma A, Dhanireddy R. Time of first stool in extremely low birth weight $(<$ or $=1000$ grams) infants. J Pediatr 1993;122(4): 626-629

24 Fang S, Kempley ST, Gamsu HR. Prediction of early tolerance to enteral feeding in preterm infants by measurement of superior mesenteric artery blood flow velocity. Arch Dis Child Fetal Neonatal Ed 2001;85(1):F42-F45

25 Thwaites CL, Yen LM, Loan HT, et al. Magnesium sulphate for treatment of severe tetanus: a randomised controlled trial. Lancet 2006;368(9545):1436-1443

26 Geboes KP, Maes B, Luypaerts A, et al. Magnesium chloride slows gastric emptying, but does not affect digestive functions. Aliment Pharmacol Ther 2002;16(8):1571-1577

27 Izzo AA, Gaginella TS, Mascolo N, Capasso F. Nitric oxide as a mediator of the laxative action of magnesium sulphate. $\mathrm{Br} \mathrm{J}$ Pharmacol 1994;113(1):228-232 